\title{
O kłopotach z rozpoznawaniem rytmu serca w zapisie EKG, część 2 - jak szukać załamków P?
}

\author{
About problems with ECG heart rhythm recognition, part 2: \\ how to identify $P$ waves?
}

\section{Rafal Baranowski}

Klinika Zaburzeń Rytmu Serca Instytutu Kardiologii w Warszawie

Rozpoznanie rytmu serca rozpoczynamy od analizy odprowadzeń kończynowych i to, czego szukamy najpierw, to załamki P. W przypadku prawidłowego rytmu zatokowego zwykle nie ma z tym problemu. Tym, co może utrudnićidentyfikację załamków P, jest blok przedsionkowo-komorowy I stopnia w zapisie z przyspieszonym rytmem zatokowym. Popatrzmy na pierwszy zapis elektrokardiograficzny (EKG).

Gdybyśmy zaczęli szukać załamków P w odprowadzeniach kończynowych i patrzyli tylko na początkowe ewolucje, to mielibyśmy problem ze stwierdzeniem, czy występują załamki P, czy też nie? Pojedyncze pobudzenie komorowe jest $\mathrm{w}$ tym zapisie bardzo pomocne $\mathrm{w}$ interpretacji rytmu serca. Jak widać, arytmia może być też pożyteczna dla pacjenta... W przerwie wyrównawczej bardzo łatwo zidentyfikujemy załamki P i ocenimy ich morfologię. Spełniają kryteria załamków zatokowych. Widoczne jest również nieznaczne wydłużenie przewodzenia przedsionkowo-komorowego. W przypadku czynności serca 120/min w takich warunkach czasowych załamki P „zlewają się” z załamkami T (ryc. 1A). Jest to dobrze widoczne w odprowadzeniu II (szczególnie

Adres do korespondencji:

prof. dr hab. n. med. Rafał Baranowski

Klinika Zaburzeń Rytmu Serca

Instytut Kardiologii w Warszawie

ul. Alpejska 42, 04-628 Warszawa

tel. 2281540 14, faks 223434502

e-mail: rbaranowski@ikard.pl na powiększonym fragmencie - ryc. 1B). Początkowo może się wydawać, że jest to kształtny załamek T. Jednak po pobudzeniu komorowym zauważymy, że jest to właśnie załamek P. Można oczywiście dyskutować, czy to na pewno tachykardia zatokowa 120/min, częstoskurcz przedsionkowy (lub okołozatokowy) 120/min. Dalszy przebieg kliniczny rozwieje te wątpliwości. W tym przypadku była to tachykardia zatokowa z prozaicznego powodu - pacjentowi skończyły się leki...

Teraz poszukajmy załamków P w zapisie pokazanym na rycinie 2.

Poszukiwanie załamków P tradycyjnie rozpoczynamy od odprowadzeń kończynowych. Tym, co od razu zwraca uwagę, są dość spiczaste, małe załamki T, dodatnie w odprowadzeniach II, III, aVF, ale ujemne w odprowadzeniu aVR. Drugi ważny element jaki musimy zauważyć, to początek zespołów QRS na przykład w odprowadzeniach II, III i aVF. Czyżby tu występowały dwa załamki R? Spójrzmy teraz na odprowadzenia V1 i V2 na powiększonym fragmencie. Czy w odprowadzeniu V1 jest zespół rsrS? Porównajmy z odprowadzeniem V2; tu zespół QRS rozpoczyna się $60 \mathrm{~ms}$ później (najlepiej to prezentuje druga ewolucja). Te wszystkie załamki $r$ to załamki P częstoskurczu przedsionkowego 180/min — próbują się „chować” w początkowej części QRS.

Poszukiwanie załamków P będziemy kontynuowali na zapisach ukazanych na rycinie 3 .

Gdzie się znajdują, jakie są i ile jest załamków P? Popatrzmy na odprowadzenie I kończynowe; załamków P nie widać, ale można zauważyć (powiększone ewolu- 

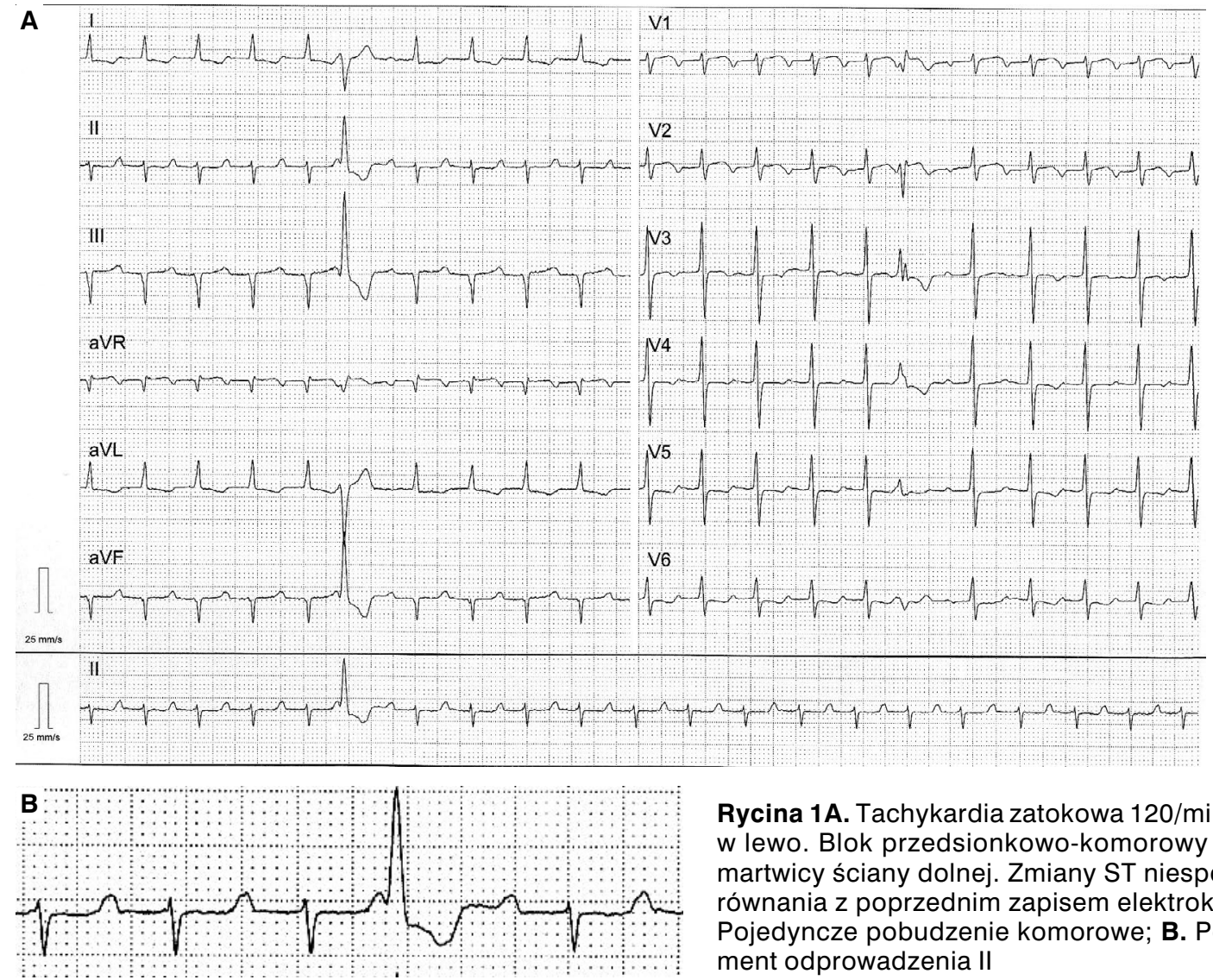

Rycina 1A. Tachykardia zatokowa 120/min. Odchylenie osi w lewo. Blok przedsionkowo-komorowy I stopnia. Cechy martwicy ściany dolnej. Zmiany ST niespecyficzne, do porównania z poprzednim zapisem elektrokardiograficznym. Pojedyncze pobudzenie komorowe; B. Powiększony fragment odprowadzenia II

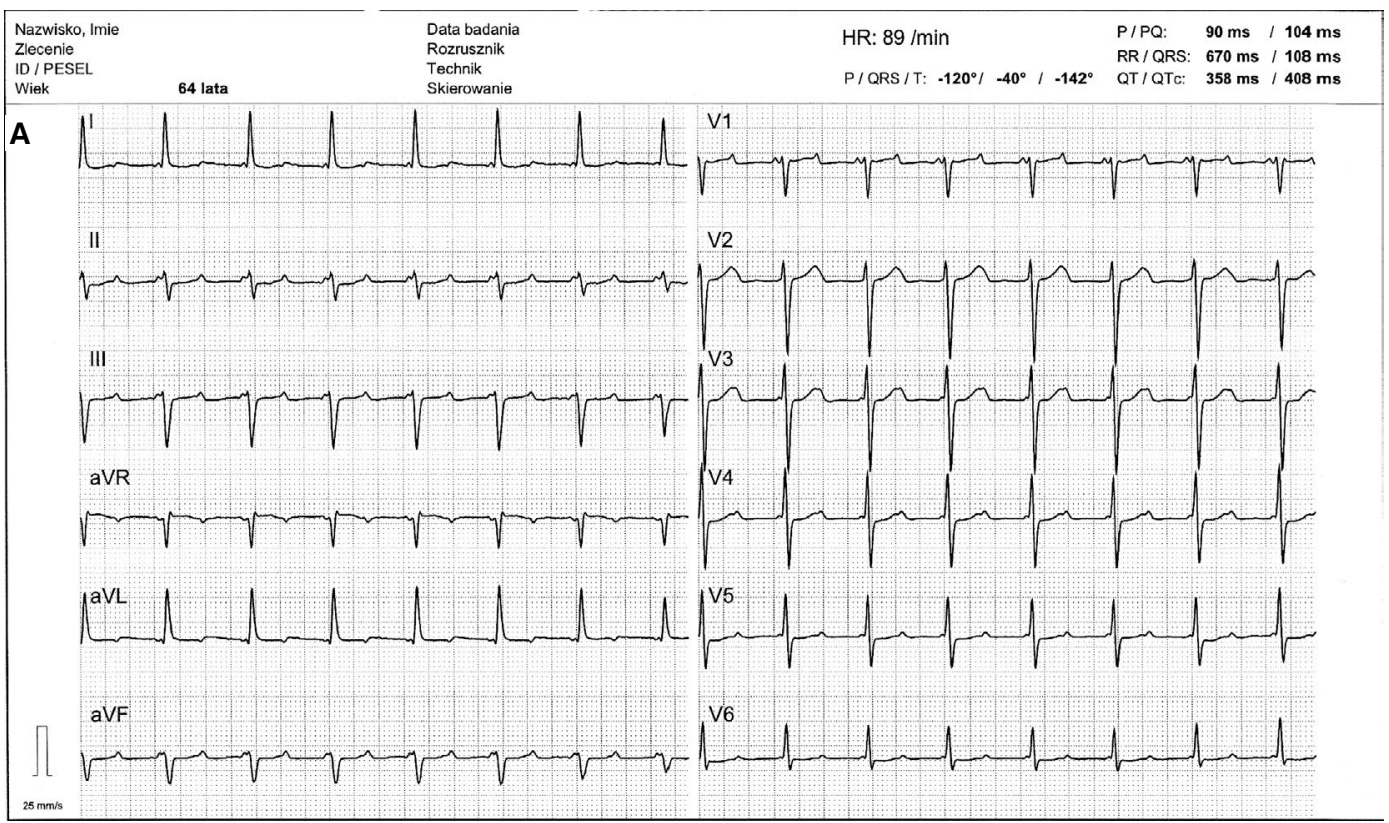

B $\mathrm{V} 1$

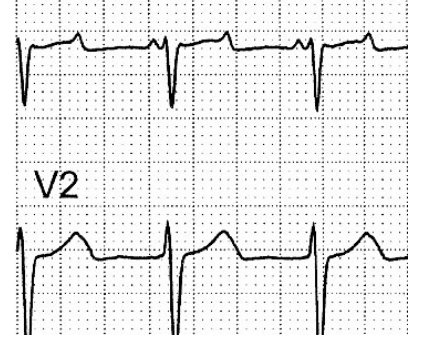

Rycina 2A, B. Częstoskurcz przedsionkowy 180/min, przewodzony 2:1 


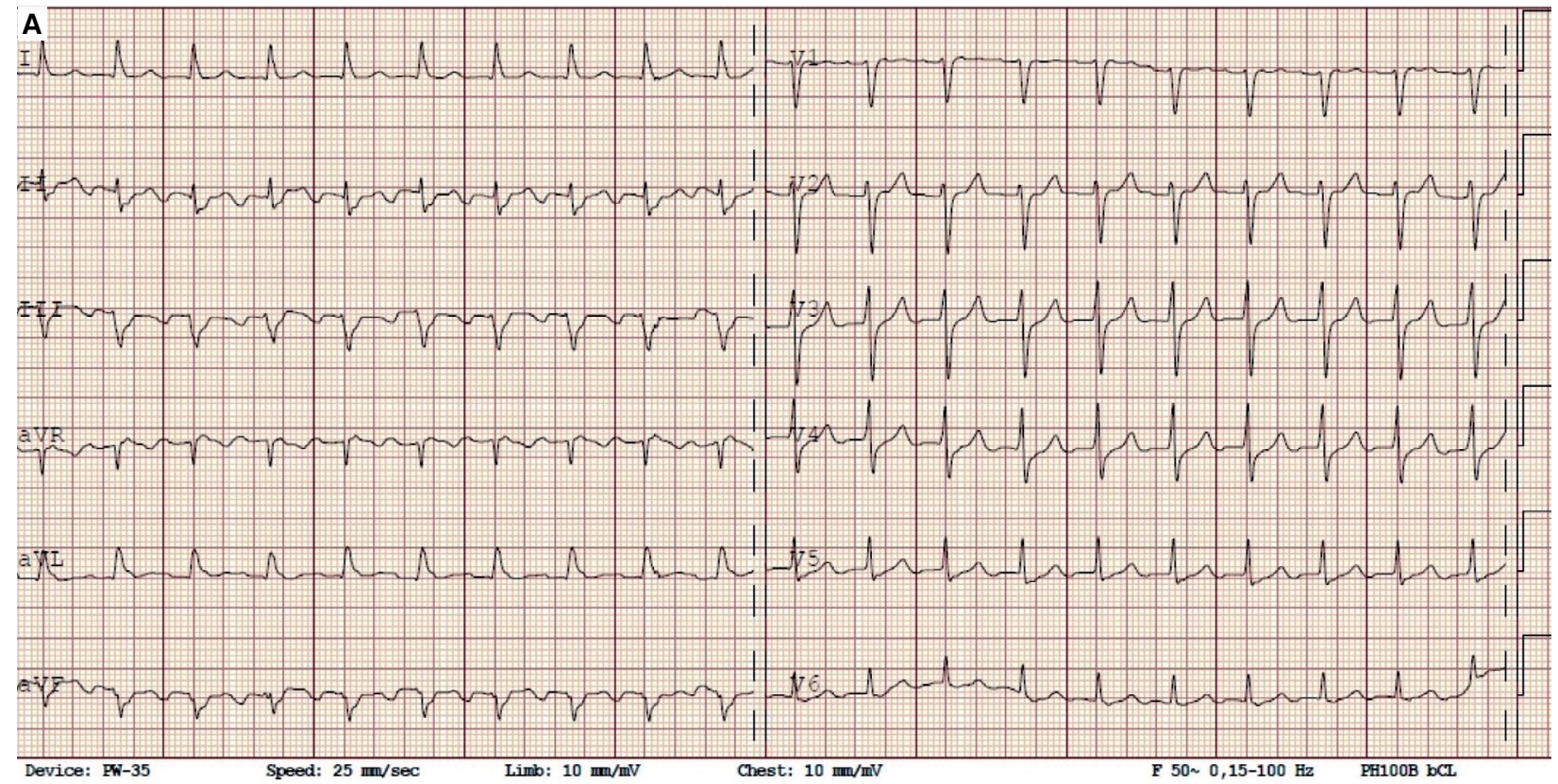

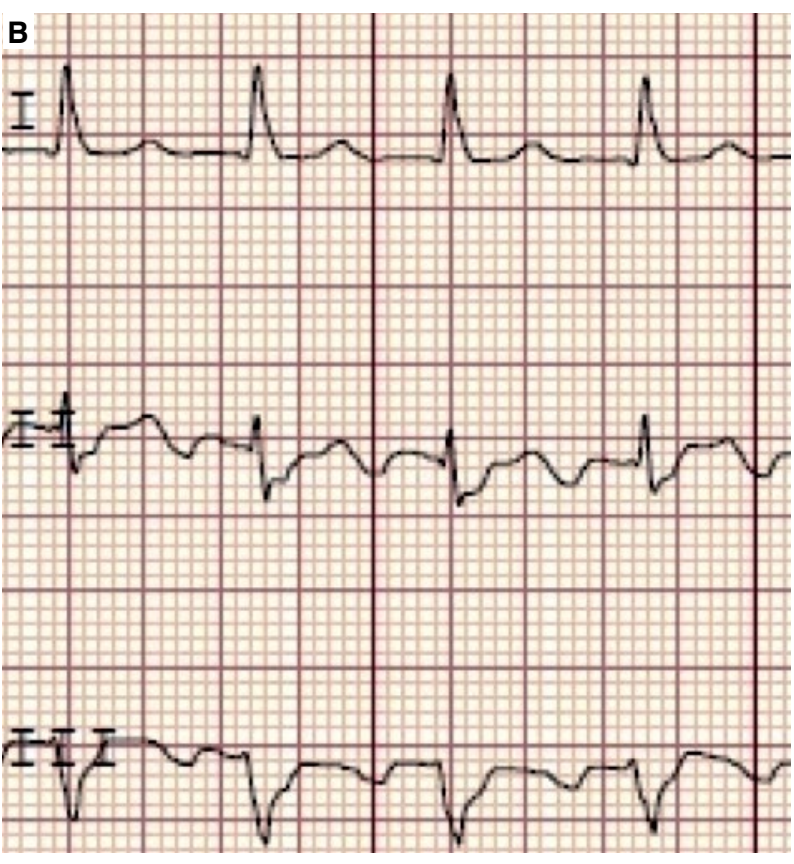

Rycina 3A-C. Częstoskurcz przedsionkowy 240/min

cje), że repolaryzacja w drugiej ewolucji kończy się na "grubej" kresce. Natomiast w odprowadzeniach II i III kończy się 60 ms później. Tyle tylko, że tam nie kończą się załamki T, ale załamki P. Czyli są ujemne w odprowadzeniach II i III, zatem nie są pochodzenia zatokowego. Czy załamków P jest tyle samo, co zespołów QRS? Otrzymaliśmy już jeden sygnał ostrzegawczy: $w$ tym zapisie EKG, w którym częstość zespołów QRS wynosi 120/ /min, występują "niezatokowe” załamki P. Drugi sygnał ostrzegawczy to fakt, że przewodzą się prawdopodob-

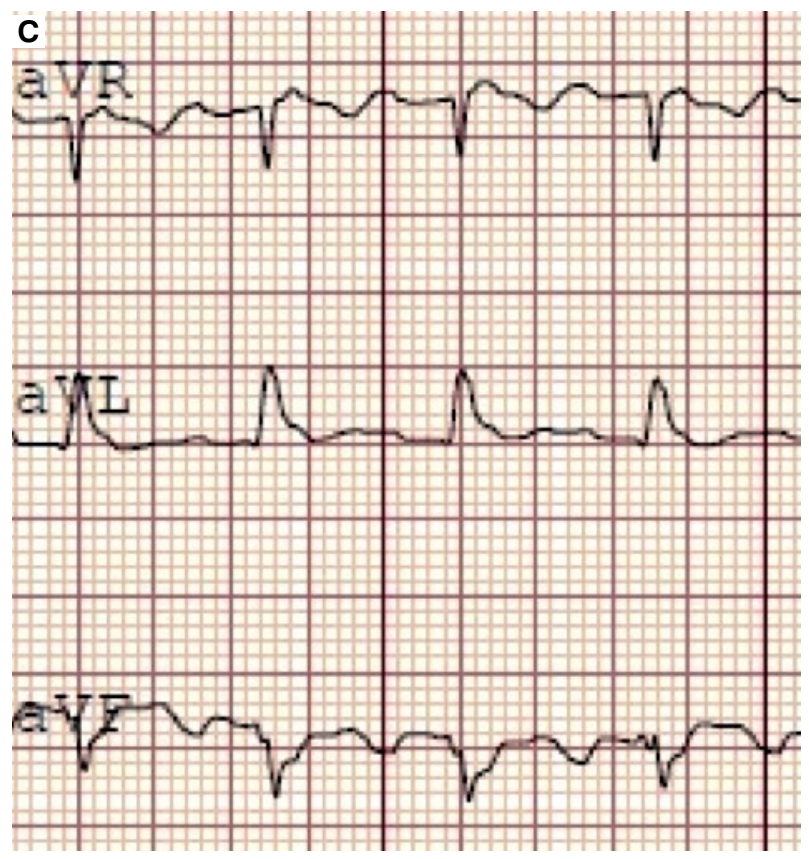

nie z blokiem przedsionkowo-komorowym I stopnia lub granicznym odstępem PQ. Teraz popatrzmy na zespoły QRS w odprowadzeniach I, II i III. Przeanalizujmy trzecią ewolucję. Załamki R „celują w grubą kreskę". W odprowadzeniu I koniec zespołu QRS jest widoczny po $60 \mathrm{ms,}$ a w odprowadzeniach II i III — po $120 \mathrm{~ms}$. Skąd ta różnica? Koniec zespołów QRS w odprowadzeniach II i III jest modelowany przez załamek P, który w sposób pozorny wydłuża czas załamków $\mathrm{S}$ w tych odprowadzeniach. Podobne pozorne wydłużenie zespołów QRS jest wi- 
doczne w innych odprowadzeniach, w których załamki P są dobrze widoczne, na przykład w odprowadzeniach aVR (pseudozałamek r), aVL (zazębienie końcowej części QRS) oraz aVF (pseudoposzerzenie załamka S).

Oczywiście nie omówiliśmy tu wszystkich wariantów "zabawy w chowanego", jaka niekiedy bywa udziałem załamków P. Chciałem jednak zasygnalizować, na jakie szczegóły zapisu warto zwracać uwagę, aby dostrzec jak najwięcej - jak posiłkować się w tej analizie różnymi odprowadzeniami. W kolejnym numerze zapraszam do kontynuacji tego wątku.

A może ktoś z Czytelników chciałby pokazać jakieś „podstępnie” schowane załamki P?

Zapraszam: ekg@ikard.pl 